\title{
The politics of meta-governance in transnational private sustainability governance
}

\author{
Luc Fransen ${ }^{1}$
}

Published online: 12 June 2015

(C) The Author(s) 2015. This article is published with open access at Springerlink.com

\begin{abstract}
In order to address challenges resulting from interactions between transnational private sustainability standard organizations, initiatives emerge that meta-govern these standards. Contrary to prevailing understandings in public policy literature, such metagovernance initiatives are mostly run by nongovernmental rather than governmental actors. While literature presents the sustainability standards field as predominantly governed by one meta-governor, ISEAL, it is hardly recognized that, alongside ISEAL, rival metagovernance initiatives are proliferating. These initiatives occur in similar sectors and issue fields, use quite similar modes of meta-governance and interact with each other. This paper explains the multiple emergence of meta-governance in the governance of sustainability standards in agriculture. It shows how meta-governance efforts are developed by political coalitions of nongovernmental actors with divergent views on and priorities in making production more sustainable. It therefore reveals the mechanism through which metagovernance of coordination problems among cross-border self-organizing governance arrangements may end up reproducing these coordination problems, rather than addressing them.
\end{abstract}

Keywords Private standards · Meta-governance - Sustainability · Governance · Regulation · Competition · Coordination

In contemporary global governance, many issue areas are governed by various governance organizations at the same time. Not only do different spatial levels of governance interact in policymaking, but so do governance organizations on similar levels (Biermann et al. 2009). Such interactions, authors hold, may either work in favour of the effectiveness of

Luc Fransen

1.w.fransen@uva.nl

1 Department of Political Science, University of Amsterdam, Nieuwe Achtergracht 166, 1018 WV Amsterdam, The Netherlands 
governance or to its detriment (Keohane and Victor 2011). One category of such governance interactions is the interaction between private sustainability standard organizations regulating social and environmental standards in global production chains, in for instance the forestry, tea, cocoa, coffee, and apparel sectors. These private standard organizations (PSOs) have proliferated in many sectors, and have often assumed competitive relationships with each other (Fransen 2011).

The coordination problems that arise because of horizontal interactions among governance organizations may be addressed through so-called meta-governance. Public policy literature analyses different types, often focused on the capacity of governments to steer or even control network-, market- and participatory modes of governance (Peters 2010; Sørensen 2006).

Recent literature, however, describes ways in which a private, nongovernmental form of meta-governance might steer interactions among PSOs in specific directions and possibly increase harmonization (Steurer 2013; Derkx and Glasbergen 2014). The chief example referenced in the literature is the International Social and Environmental Accreditation and Labelling Alliance (ISEAL Alliance, or ISEAL), a membership organization for PSOs that includes among others Rainforest Alliance and the Forest Stewardship Council. Recent studies examine ISEAL's activities, contributing to the picture that ISEAL is the chief and reigning meta-governance initiative that meta-governs PSOs focused on sustainability (Auld 2014; Bernstein 2011; Dingwerth and Pattberg 2009; Loconto and Fouilleux 2013; Marx and Wouters 2014; Reinecke et al. 2012).

However, it is hardly recognized and theorized that alongside ISEAL, other efforts at meta-governance are proliferating. Such programmes often focus on issue areas and industries similar to those of ISEAL. These programmes therefore develop complex interactions with ISEAL, with each other, and with PSOs, their business members and civil society organizations (CSOs).

This paper addresses the question why private, nongovernmental forms of meta-governance addressing competition among PSOs, themselves proliferate and compete. Answering this question will, first, advance the literature on transnational private sustainability standards by more accurately portraying and explaining the prevailing complex dynamics of multi-layered governance in this issue field. Second, the paper contributes to a broader literature on the promise and perils of meta-governance, by showing how metagovernance may evolve when governmental organizations take the back seat. A selforganized, nongovernmental form of meta-governance addressing coordination problems may then reproduce the problems of the self-organized governance it is supposed to address. The paper shows how the diverging political agendas towards standardization among different categories of nongovernmental actors that engage in governance and meta-governance lead to this result. The paper therefore describes and explains a specific category of meta-governance failure, relevant for other issue fields in which meta-governance is required to steer coordination problems among market actors across borders. And it emphasizes the significance of political discord in the evolution of governance and metagovernance (cf. Jessop 2003; Porras-Gómez 2014).

The analytical argument is developed based on a comparative case study of the private governance and meta-governance of sustainability issues of two agricultural commodities, based on original interview material, participatory observation and policy document analysis. The findings pertain to these cases, while allowing for development of an explanatory theory of the multiplicity of meta-governance that may be used for hypothesizing about transnational governance of economic practices crossing jurisdictional borders more generally. 
The "Conceptualizing meta-governance in light of transnational private sustainability governance's challenges" section introduces literature on the meta-governance of transnational private sustainability governance and the approach of this study. The "Methodology and methods" section discusses the methodological approach. The "Private sustainability standards in agriculture" section briefly introduces PSOs in agriculture. In "The proliferation of nongovernmental meta-governance in agriculture" section, the empirical cases that illustrate the argument are discussed. The final "Conclusion" section offers a conclusion.

\section{Conceptualizing meta-governance in light of transnational private sustainability governance's challenges}

\section{Proliferation of PSOs in transnational private sustainability governance}

PSOs set social and environmental standards across borders, in particular in global production chains that run from developing to developed countries. Nowadays, they are primarily developed and governed by CSOs that have environmental and developmental advocacy goals (such as World Wildlife Fund and Solidaridad) and/or by industry representatives selling or branding end products (Potts et al. 2010; cf. Porter and Ronit 2006). Business participants voluntarily apply PSOs' standards, which invoke commitment to a corporate responsibility agenda. The voluntary nature of the standards helps ensure compatibility with existing World Trade Organization (WTO) agreements. Moreover, by relying on third-party assessments of firm compliance, analogue to the technical standards of the International Organization for Standardization (ISO), PSOs moreover seek to circumvent a critique that the fox is guarding the henhouse (Kollman and Prakash 2002).

Proliferation of and subsequent competition between PSOs emerges once different sets of actors create different standard-setting approaches within one issue area and/or industry. This is now the case in private sustainability standard setting for the production of coffee, cocoa, tea, apparel, forestry products, minerals, various resources used for biofuels and other products (Marx and Wouters 2014). This competition potentially has short- and medium-term consequences of concern for policymakers.

Fransen (2011) identifies five of these. First, private standard competition increases confusion among parties that are supposed to participate in, or, through their consumer decisions, support PSOs. Where organizations work with product labels, consumers and firms may not be able to distinguish different labels and may then doubt sustainability labelling as a whole. Second, implementation of different private standard-setting approaches may lead to contradictions between standard implementation requirements at industrial facilities. Third, different standards may increase costs of implementation for producers in developing countries. Fourth, competition between standards increases the costs for organizations that provide funding to PSOs, such as CSOs and governmental development agencies. Fifth, competition between PSOs may induce a race to the bottom, if organizations adjust standards and regulatory procedures downwards in order to attract firms that perceive demanding standards as costly.

\section{Meta-governance in transnational private sustainability governance}

Meta-governance is defined in the public policy literature broadly as "the governance of governance", and refers to the need to steer how governing takes place. This need is related 
to, first, broader failures at governing (Jessop 2003, 2011), which may for instance result from oversimplifying the problem to be governed, erratic inference about the roots of problems, misfits between the scale of governance and the scale of problems, or coordination problems among governing parties. Second, meta-governance is invoked as a response to the more specific challenges of nonhierarchical modes of governance that have gained momentum in past decades as alternatives to hierarchical top-down steering by national governments. These modes may apply market mechanisms, involve network structures of exchange among policymakers, or participatory models of decision-making including citizens and interest groups (Peters 2009; Porras-Gómez 2014). For this strand of literature, meta-governance therefore means the governance of self-governance, or, alternatively, the regulation of self-regulation or the organization of self-organization.

In addition, Jessop (2011: 113-116) identifies four modes of meta-governance: redesigning of markets so that incentives are better aligned and improve outcomes; constitutional design innovations that adjust the mandate and scope for action of relevant parties; redesigning of network relations so that interactions among relevant governing parties may become more efficient and effective; and interventions designed at promoting trust, loyalty and commitment among governing parties that smoothen governance processes.

Meta-governance of specifically transnational private sustainability governance is focused on transnational flows of economic exchange that are likely to exceed the jurisdictional borders of most governmental entities. Notably, it is performed to a considerable degree by nongovernmental organizations, with governmental organizations often refraining from substantial involvement in meta-governance beyond facilitation and funding. Furthermore, due to the multiplicity of PSOs, meta-governance is likely to be focused on coordination problems.

Table 1 depicts the types of meta-governance of transnational private sustainability governance identified in literature so far. Meta-governance may occur reflexively due to the actions of PSOs themselves. Increased recognition of successes and failures, and policy revisions as a result of comparison with peer PSOs can steer PSO interactions overall in the direction of more harmonization, or in the direction of sustained divergence (Overdevest 2010; Glasbergen 2011). But the literature also reveals that such reflexive actions may be limited in terms of the organizations involved or the substantive revisions made (Reinecke et al. 2012).

Studies, moreover, show that meta-governance of PSOs could occur through the efforts of national and international governmental institutions. Schleifer (2013), among others, describes how the European Union (EU) can stimulate PSOs to adjust their approaches in

Table 1 Meta-governance of PSOs in transnational sustainability governance, as discussed in the literature

\begin{tabular}{lll}
\hline & Nongovernmental & (Inter)governmental \\
\hline $\begin{array}{l}\text { Reflexive/self- } \\
\text { directed }\end{array}$ & $\begin{array}{c}\text { Revisions by PSO policy makers, sometimes as } \\
\text { result of comparison with other PSOs } \\
\text { (e.g. Overdevest 2010; Reinecke et al. 2012) }\end{array}$ & $\begin{array}{c}\text { Not applicable (because of } \\
\text { nongovernmental nature of PSOs) }\end{array}$ \\
$\begin{array}{l}\text { Directed at } \\
\text { multiple } \\
\text { parties }\end{array}$ & $\begin{array}{c}\text { i.e. ISEAL (e.g. Bernstein 2011; Auld 2014 } \\
\text { i.ernmental meta-governance initiative, }\end{array}$ & $\begin{array}{c}\text { National public procurement policies; } \\
\text { EU background criteria (e.g. Schleifer } \\
\text { 2013; Gulbrandsen 2014) }\end{array}$ \\
\hline
\end{tabular}


certain sustainability issue areas by, for instance, creating background criteria for sustainable production to which businesses must adhere, and which may conform to alreadyexisting PSO standards. Similarly, governments can sometimes meta-govern PSOs through public procurement policies that set requirements for sustainable production of goods bought by governments (Glasbergen 2011; Gulbrandsen 2014).

The literature also recognizes limits to a governmental or intergovernmental role in meta-governance of particular transnational private sustainability standards that govern commodities connecting producers in the Global South to consumers in the Global North. As Bartley (2003) has noted, international institutions governing the global economy advance the free flow of goods across borders, and delimit political and judicial space for governments to contain or discriminate in flows according to their sustainability aspects. International trade agreements are relatively strong and extensive, relative to the scope and enforceability of existing international labour and environmental instruments. Trade agreements therefore may inhibit explicit meta-governance from governments on social and environmental issues, as interventions in PSOs governing cross-border trade relationships may be viewed as promoting barriers to trade, and therefore, protectionism. And, similarly, explicit governmental preference for particular types of PSOs inside the EU and the United States (US) can be legally challenged with reference to competition policy regulations within these jurisdictions. The result is that the governmental and intergovernmental meta-governance of PSOs that govern globally spanning production chains has so far been covert and indirect. Governments and intergovernmental organizations have funded initiatives of nongovernmental efforts towards meta-governance, have facilitated various categories of nongovernmental actors coming together on a meta-governance effort, and have given political support to meta-governance efforts to address PSO competition (Derckx and Glasbergen 2014). But more substantive decisions on the scope and content of meta-governance are left to nongovernmental actors.

Possibly as a result of this, the literature identifies a third form of meta-governance as largely predominating, next to reflexive meta-governance and (inter-)governmental metagovernance. Here, nongovernmental organizations develop meta-governance institutions and initiatives to address coordination problems among PSOs, sometimes funded or facilitated by governmental organizations such as development agencies or intergovernmental agencies (Derckx and Glasbergen 2014). Meta-governance tools are created in a policymaking setting that is inclusive to (at least some) parties already engaged in private standard setting, and tools are applied voluntarily. In this category, ISEAL receives exclusive attention in the literature (Auld 2014; Bernstein 2011; Dingwerth and Pattberg 2009; Loconto and Foullieux 2013; Marx and Wouters 2014; Reinecke et al. 2012).

\section{Multiplicity in meta-governance of transnational private sustainability governance}

However, in various industries where PSOs compete over sustainability standard setting, ISEAL is not the only meta-governor. Instead, various programmes parallel to ISEAL aim to meta-govern similar sustainability issues and PSOs. These programmes have existed for quite some time next to each other, mostly without engaging in elaborate forms of coordination or collaboration. The possibility of such meta-governance proliferation has been discussed some years back in the literature (Mutersbaugh 2005), but has never been explored further empirically nor theorized more elaborately. Figure 1 offers a stylized overview of contemporary nongovernmental meta-governance programmes in transnational private sustainability governance. It includes actors subject to standardization and 


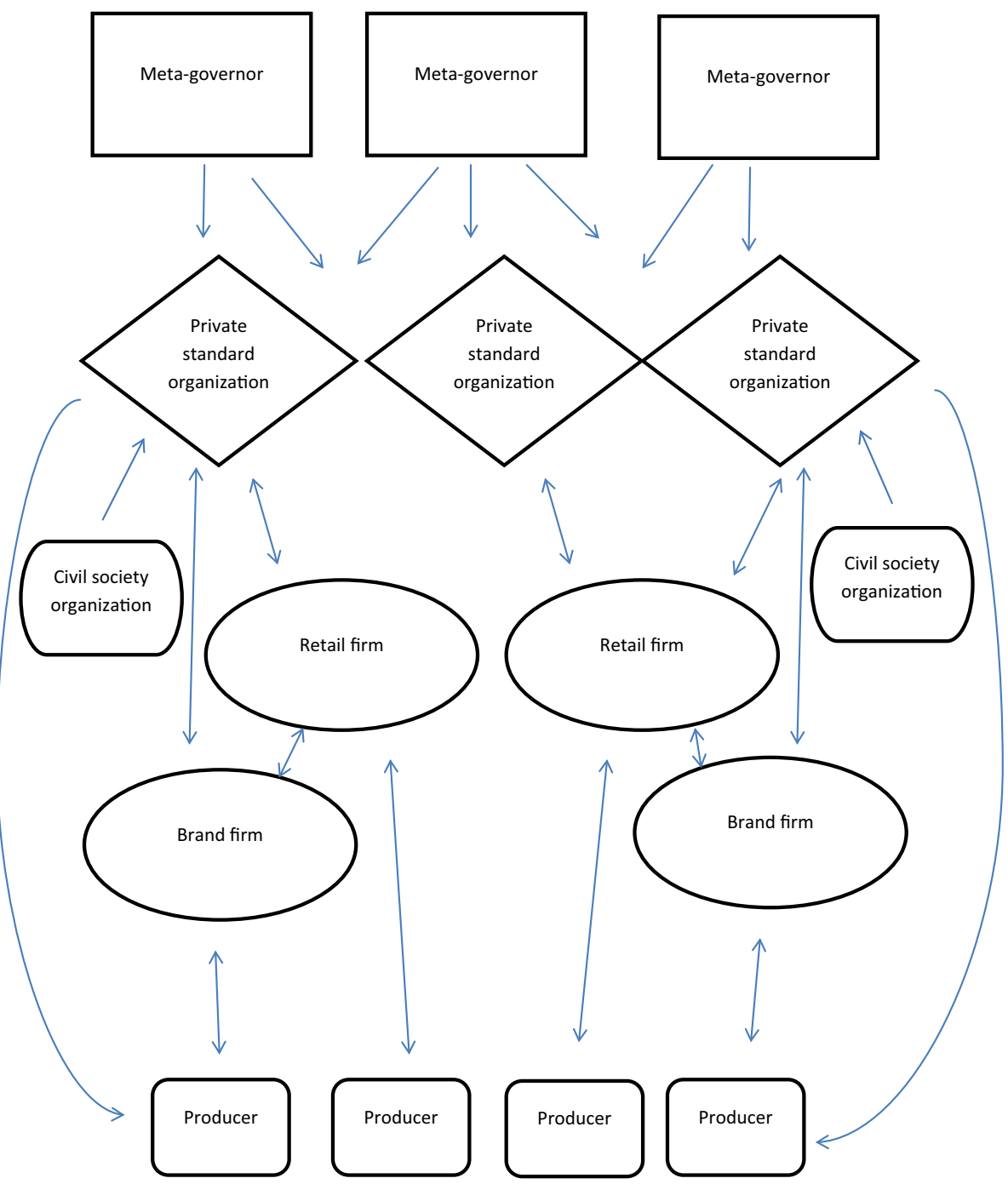

Fig. 1 Standardization and meta-governance in transnational private sustainability governance

their mutual formal institutional relations (including governance functions and recurring trade patterns). For now, the figure brackets the possible institutional relations between these actors on the one hand and the meta-governance initiatives on the other, as these will be explored in the next sections.

Nongovernmental meta-governance of private sustainability standard setting so far has predominantly been analysed either through a sociological-ideational lens, or through a more rationalist-economic and problem-solving lens (cf. Peña 2014: 5). Accordingly, emphasis is on ISEAL's role in promoting norm convergence among and legitimacy for PSOs, or on its role in addressing the coordination problems inherent to multiple PSOs focusing on similar issues (cf. Marx and Wouters 2014). Bernstein (2011) for instance 
focuses on ISEAL's efforts to create norms for appropriate governance among PSOs in terms of accountability, inclusiveness and transparency in standard setting (cf. Dingwerth and Pattberg 2009). Meanwhile, Auld (2014) discusses ISEAL in terms of its ability to manage policy- and problem-interactive effects resulting from the issue boundaries set by PSOs' advancing sustainability (cf. Steurer 2013).

Recently, the literature also offers a view of ISEAL's practices that focuses on political dimensions. Rather than emphasizing the problem-solving aspect of meta-governance, it discusses how meta-governance like ISEAL's may involve particular political perspectives on the definition and organization of sustainability practices. And rather than describing meta-governance as part of a macro-structure of norms, it views meta-governors as actors with ideas, strategies and organizational interests in their own right. Ideological differences, contentiousness of policies, divergence of political agendas and power thus play a more prominent role in interpreting meta-governance (Loconto and Fouilleux 2013; Reinecke et al. 2012; cf. Glasbergen 2011: 204).

These studies therefore implicitly recognize that ISEAL advances a particular view on sustainability standard setting that may be rivalled by contending views. Moreover, part of ISEAL's purpose is to cater to particular organizational needs that may not be agreed to nor be acknowledged by all relevant actors involved in making global production chains sustainable. Still, none of these studies devotes much attention to the possibility that other meta-governors might arise challenging the position of ISEAL. Willingly or unwillingly, therefore, all articles discussed in this review paint a picture of ISEAL and their PSO members as being in the driving seat of meta-governance.

Why are there many meta-governors addressing coordination among PSOs and not one? It would be tempting to attribute the proliferation of meta-governance initiatives chiefly to the nongovernmental type of meta-governance, which may invite meta-governance by a multitude of nongovernmental actors. However, we should bear in mind that globally spanning cross-border flows, such as the production chains subject to governance by PSOs, might be equally hard to meta-govern uniformly and cohesively by governmental organizations. Even intergovernmental organizations with a broad geographic and political reach such as the different branches of the United Nations (UN), the WTO and the intergovernmental development banks are known to develop conflicting, contradicting or overlapping policies and instruments towards the meta-governance of state behaviour in many issue areas (Alter and Meunier 2009). The intergovernmental meta-governance of sustainability issues as addressed in state policies is arguably as fragmented as the competitive field of PSOs focused on sustainability policies of businesses (Biermann et al. 2009).

We may also expect multiplicity as a result of meta-governance taking place at different scales (local, national, regional), or through different modes of meta-governance (e.g. market design focused versus network design focused) being employed (cf. Jessop 2011). But as we will see below, there is not that much variation in the scale of metagovernance nor in the modes of meta-governance. Most meta-governance initiatives discussed below have a similar mix of facilitative support from governments and practical control of the meta-governance agenda by nongovernmental actors, and focus on one or more categories of sustainable practices for commodities. And most meta-governance initiatives effectively mix efforts at re-designing networks of policymakers with efforts at market design in terms of their mode of meta-governance.

Prevailing understandings in the PSO-focused literature also have difficulty coming to terms with persistent meta-governance multiplicity and the coordination problems that may result from it. From both a rationalist problem-solving perspective and a sociologicalideational perspective, there is no logical foundation for the persistent existence of various 
meta-governors making similar interventions focused on the same issue. In both accounts of meta-governors as problem-solving devices and as legitimizing forces, meta-governance programmes would be most likely to converge. Alternatively, they would through interaction divide labour in a way that would be conducive to coordination and learning among PSOs (Zeitlin 2011), or at least re-focus activities so that duplicity would lessen. Each meta-governance initiative could then effectively occupy its own niche in terms of interventions directed at PSOs (Abbott et al. 2013).

\section{The politics of meta-governance multiplicity}

This paper advances a viewpoint that follows up on the political perspective of metagovernance previously discussed. It connects these insights to literature that has previously dealt with political interactions in and among PSOs, and in the organization of transnational production chains. This approach also draws from a perspective on metagovernance from the broader public policy literature, emphasizing the interests of actors engaging in governance and their struggle in shaping governance according to their preferences (Jessop 2003; Porras-Gómez 2014). Particularly relevant here is Bob Jessop's observation that governance and meta-governance alike involve "the organization of the conditions of governance in terms of their structurally inscribed strategic selectivity, i.e., in terms of their asymmetrical privileging of some outcomes over others" (2003: 13, emphasis added).

Accordingly, a given set of private sustainability standards is a manifestation of a political perspective on sustainability, developed and governed by a coalition of actors all with their own particular stakes in the industry and the issue area, which they try to defend or advance by being standard setters and governors (Bartley 2007; Jenkins 2002). The proliferation of different PSOs presenting different sustainability perspectives for industries signifies diverging views on what is appropriate standard setting (cf. Reinecke et al. 2012). Notably, actors' viewpoints may differ if they represent a corporate or a civil society interest, a public or private sector interest, or a developed or a developing country interest (cf. Dingwerth 2008; Jenkins 2002).

In addition, studies emphasize intra-industrial frictions that structure PSO emergence, proliferation and interactions (Bartley 2007). Following approaches to geography and political economy, emphasis is on possible conflict and differences in interest among firms: horizontally in competitors' markets and vertically in (cross-border) production chains (Gereffi et al. 2005). Depending on issues of power and redistribution, such as who generates the highest profit, who has key access to end markets, and who has access to scarce resources such as raw materials, firms may prefer different PSO approaches. Or they may prefer to follow certain firms into a particular PSO, while staying away from others. Private standards are intertwined with such competition and supply chain considerations because implementation of private standards affects both reputation in horizontal competitive markets and vertical buying-selling relationships (Gereffi et al. 2005: 85). Accordingly, studies of the politics of transnational private sustainability governance particularly stress differences in the stakes of retail-focused firms, branding-focused firms and bigger and smaller producers in forestry, apparel and agriculture (Bartley 2007; Mutersbaugh 2005).

If the direction of transnational private sustainability governance taken by PSOs matters to actors, then it is only logical that meta-governance also is of concern to them, as it may advance or diminish the space for particular approaches to sustainability. Meta-governors, much like PSOs, should be analysed in terms of the actors that play a role in developing 
them, the specific approach to governance and the priorities set for the sustainability issue at hand. By demonstrating how substantially divergent views on what is appropriate governance relate to such political-economic positions, we are able to theorize why metagovernors proliferate and persistently attempt to govern PSO interactions in different ways.

The empirical sections below describe the emergence of multiple meta-governance programmes in transnational private sustainability governance of the coffee and cocoa sectors and reveal the recurring interactions among meta-governors that result from it. As we will see, multiple meta-governance programmes arise as a result of divergent objectives among global retailers, large product brand owners, technical standard setters and professionals representing PSOs. These actors' perspectives differ depending on their priorities in terms of developing more sustainable production. This leads them to different diagnoses of the challenges of PSO interactions, and to persistent support for different meta-governance solutions.

\section{Methodology and methods}

This study uses a combination of deductive and inductive logic to specify the research approach, analyse the empirics and arrive at conclusions. For the study of the origins of multiplicity in meta-governance in transnational private sustainability governance, it focuses on the field of sustainable agriculture. This is one of the key sectors discussed in transnational private sustainability governance literature, and one of the central concerns of ISEAL. Because of this focus, descriptive empirical claims can be examined deductively, in particularly testing the claim in literature that ISEAL is a central meta-governor. By researching in particular cocoa and coffee production in the agricultural sector, dynamics in two important and broadly studied commodities of transnational private sustainability governance are illuminated. For the purpose of examining descriptive claims on metagovernance, these commodities serve as crucial cases, or in Gerring's (2007: 120-121) terminology, as disconfirmatory cases. The following meta-governance initiatives are analysed: ISEAL, the Common Code for the Coffee Community (4C), the Dutch Sustainable Trade Initiative (Initiatief Duurzame Handel, IDH), the Global Social Compliance Programme (GSCP) and the European Committee for Standardization (Comité Européen de Normalisation, CEN).

Through a focus on coffee and cocoa, causal claims of this study are developed inductively. An inductive research approach is considered appropriate since the phenomenon to be explained is new, deviant from prevailing expectations in the literature and currently under-theorized (George and Bennett 2005: 74). On the one hand, for the purposes of the causal story, coffee and cocoa serve as representative commodities for the field of sustainable agriculture, where for most commodities three meta-governors exist side by side (IDH, GSCP and ISEAL). Information on these initiatives and their interrelation therefore could be generalizable throughout the sector. On the other hand, in both cocoa and coffee, additional meta-governance initiatives have arisen (CEN and 4C, respectively). This means that coffee and cocoa serve as more extreme cases in terms of the value of the dependent variable (proliferation of meta-governance). This makes generalizability and representativeness questionable, but importantly, it allows for more openended exploration of causal mechanisms underlying emergence of meta-governance initiatives (Gerring 2007: 104-105). Cocoa and coffee are interdependent cases for the emergence of IDH, GSCP and ISEAL, and largely independent cases in terms of the rise of 
$\mathrm{CEN}$ and $4 \mathrm{C}$. For this reason, there is a wealth of within-case and across-case observations that may be used for analysis.

Process tracing is used next to comparative logic to inductively develop the causal argument about proliferation and duplication in meta-governance (George and Bennett 2005). Comparative logic allows particularly for identification of variance in actor's viewpoints on and interests in sustainability and activities towards meta-governance. Process tracing serves the identification of decision-making processes and interactions in and among firms, CSOs, PSOs and meta-governance initiatives, as evidenced in the empirical narrative provided in subsequent sections.

The analysis is based on 35 semi-structured interviews with representatives of metagovernors, PSOs, firms, CSOs and government, who were selected for their varying roles in setting up and participating in various meta-governance initiatives. The majority of these interviews were conducted between May 2011 and July 2013. Interviews covered the origins of meta-governance, the actors involved in setting up the initiatives, respondent perspectives on meta-governance and sustainability, the relationship among PSOs and the relationship among meta-governors. Additional interview material from 2006 to 2008 was used, adding further insight into the genesis of meta-governance arrangements. This material was originally gathered for a different research project on private sustainability governance, but respondents were asked broadly similar questions. Interviews were transcribed and then hand-coded for information allowing process tracing of decision-making and unfolding events among PSOs and meta-governors.

Parallel to interviewing and interview data analysis, publicly available policy documents of all mentioned actors, dating between 2002 and 2013, were studied and similarly hand-coded. Insights from participant observation during four public professional workshops and conferences, attended between September 2008 and July 2013, are used to further validate the observations taken from the data.

An inductive set-up means that theory is generated, and the explanation follows from empirical analysis, rather than preceding it. The results serve as findings with regard to the selected cases and as propositions for a wider field of meta-governance of cross-border economic and sustainability issues. While research partially relying on process tracing may not always allow us to fully rule out competing explanations that could have been unearthed as alternatives to the presented theory (George and Bennett 2005: 220-222), empirical stages in the process leading to the outcome of analytical interest may be discussed in light of possible alternative theoretical interpretations. The empirical sections below will devote attention to such competing interpretations in some key stages of the narrative, and will argue that the inductively developed theoretical framework offers the most plausible interpretation.

\section{Private sustainability standards in agriculture}

Agricultural commodities have been subject to transnational private standardization inspired by four distinct agendas. First, beginning in the 1980s, various standards emerged that raised the bar on food safety issues, as a result of increased consumer concern about health effects and about the increasingly global organization of food product chains, including, among others, the various good agricultural practices (GAP) now organized by the GlobalGAP standards body. Generally, this standard-setting process has been driven and controlled by the largest European and American retailers (Wouters et al. 2012). 
Second, agricultural chains have been subjected to attention from CSOs seeking to use cross-border trade as levers for more equity between Northern and Southern economic activity, and the application of social and environmental standards. The alternative trade movements that eventually led to the Fairtrade label began to work towards trading products under more equitable terms as early as the 1960s, offering a price premium to small and poor producers in developing regions. Political debates about globalization, and the increased popularity of "corporate responsibility" as a term denoting firms' progressive activities, spurred a movement to bring these standards into mainstream business. The global organization of various national fair trade standards into the Fairtrade Labelling Organization (FLO) went hand-in-hand with this shift (Raynolds and Long 2007).

Third, environmental conservation groups contributed to private standardization. Their focus was either on particular animal species or the conservation of the rainforest, through for instance the Smithsonian Center's Bird Friendly label. Other CSOs concerned about the usage of pesticides and hormones developed organic labels for sustainably grown coffee. Organic labels proliferated nationally, and in the end became organized globally in the International Federation of Organic Agriculture Movements (Auld 2010).

Fourth, industry players that sought to respond to increased demands for corporate responsibility in food production also developed mainstream, industry-focused sustainability standards, together with CSOs that wanted to assist in mainstreaming sustainable production. Utz Kapeh, later renamed Utz Certified, was developed by Dutch retailer Ahold alongside developmental NGOs and focused on large coffee roasters and retailers in Europe. In the US, the Rainforest Alliance (RA) catered to industry players as well (Kolk 2011). Recently, the demand for biofuels spurred the development of standards for energyproducing crops, including commodities that can also be used as food ingredients (Schleifer 2013).

Subsequently, coffee, cocoa and tea became the most prominent products for standard proliferation and competition. Arguably the most substantial contribution to standard proliferation was made by fair trade- and corporate responsibility-inspired standards for socio-economic and environmental conditions of production. ${ }^{1}$

\section{The proliferation of nongovernmental meta-governance in agriculture}

This section illustrates how meta-governance programmes have proliferated and traces the emergence of and interaction between different initiatives. Table 2 gives for advance reference a stylized overview of the empirical argument below by matching actors, perspectives and stakes to particular meta-governance initiatives.

\section{PSOs and their ISEAL Alliance}

ISEAL Alliance emerged out of discussions among representatives of PSOs, CSOs and academics in 1999. PSOs recognized similarities in approach and organization of standard setting across issue areas and sought a common platform to stimulate learning based on practice. In addition, PSOs sought an organization to represent their common interests on the governmental and intergovernmental level, and to private parties. Since PSOs take a position somewhere in between the WTO, the ISO, the UN agencies and secretariats

1 Food safety concerns were less salient there than in fresh produce categories of food. Both animal protection and organic-certified products developed a market niche. 
Table 2 Actors, agendas and meta-governance

\begin{tabular}{|c|c|c|c|}
\hline Brand firms & Retail firms & $\begin{array}{l}\text { Technical standard } \\
\text { professionals }\end{array}$ & $\begin{array}{l}\text { Private sustainability standard } \\
\text { organizations }\end{array}$ \\
\hline \multicolumn{4}{|c|}{ Perspective on coordination problem } \\
\hline $\begin{array}{l}\text { Competition } \\
\text { barrier to scaling } \\
\text { up certification }\end{array}$ & $\begin{array}{l}\text { Competition complicating } \\
\text { buying decisions and } \\
\text { compliance policies }\end{array}$ & $\begin{array}{l}\text { Competition leading } \\
\text { to brand and retail } \\
\text { confusion }\end{array}$ & $\begin{array}{l}\text { Competition negatively } \\
\text { affecting credibility and } \\
\text { effectiveness of PSOs }\end{array}$ \\
\hline \multicolumn{4}{|l|}{ What is at stake? } \\
\hline $\begin{array}{l}\text { Brand supply } \\
\text { chain security }\end{array}$ & Retail sales and reputation & $\begin{array}{l}\text { Market for standard } \\
\text { services }\end{array}$ & Support and funding for PSOs \\
\hline \multicolumn{4}{|c|}{ Proposed modes of meta-governance (cf. Jessop 2011) } \\
\hline $\begin{array}{l}\text { Market-design; } \\
\text { network-design }\end{array}$ & Market-design & Market-design & $\begin{array}{l}\text { Market-design; network-design; } \\
\text { trust-building interventions }\end{array}$ \\
\hline \multicolumn{4}{|l|}{ Specific interventions } \\
\hline $\begin{array}{l}\text { Baseline } \\
\text { standards; } \\
\text { roundtables }\end{array}$ & $\begin{array}{l}\text { Benchmarking and } \\
\text { comparison }\end{array}$ & Baseline standards & $\begin{array}{l}\text { Standards for standard setting; } \\
\text { roundtables; comparison; } \\
\text { community building }\end{array}$ \\
\hline \multicolumn{4}{|c|}{ Corresponding initiatives } \\
\hline $\begin{array}{l}\text { 4C; Sustainable } \\
\text { Trade Initiative } \\
\text { (IDH) }\end{array}$ & $\begin{array}{l}\text { Global Social Compliance } \\
\text { Programme }\end{array}$ & $\begin{array}{l}\text { CEN Cocoa } \\
\text { standard }\end{array}$ & ISEAL \\
\hline
\end{tabular}

dealing with the environment and sustainable development, and bilateral and multilateral development donors, PSOs looked for representatives to defend and advance their positions in these forums.

After 2000, ISEAL began to combine these functions as an NGO with PSOs as members, first predominantly for Fairtrade, organic certifiers, the Marine Stewardship Council, and the Forest Stewardship Council, but later on for more PSOs (Bernstein 2011; Loconto and Fouilleux 2013). Collaboration and learning was principally to be focused across sectors and issue areas, but potentially ISEAL would also be able to function as a springboard for harmonization and coordination among competing PSOs in specific sectors. The most eyecatching initiative along this line was the development of a discussion platform for sustainable agriculture certification, the Social Accountability in Sustainable Agriculture project (SASA), which studied possibilities for harmonization among fair trade, organic and mainstream business standard labels and finished in 2004 (Mutersbaugh 2005).

In the course of the 2000s, ISEAL began meta-governance by developing standards for good practice for the development and operation of PSOs. These meta-standards (or: standards about standard setting) have directly applied to its members, and have also served as a template for appropriate standard setting beyond them (Bernstein 2011). Currently, ISEAL meta-standardizes standard development, compliance assurance, standard governance and standard evaluation. It has also recently agreed on credibility principles, which describe what core values underlie appropriate forms of private sustainability standard setting (ISEAL 2013a). By doing this, ISEAL arguably engages in market design as meta-governance: creating a divide within the market for PSOs between its own members and others, where the former is deemed to be more credible and leading in terms of fairness and effectiveness. Second, ISEAL, through a host of recurring annual 
conferences and meetings, and social media tools, seeks to bring together what it calls the "standard community" (ISEAL 2011). It therefore also organizes interventions aimed at increasing trust, as a mode of meta-governance that promotes PSO policymakers sense of belonging and like-mindedness.

Members of ISEAL observe PSO competition as a problem of effectiveness for PSOs and as a reputation challenge for the PSO "sector" as a whole. ${ }^{2}$ This is why for agriculture, ISEAL has recently also opted for a network design mode of meta-governance. It organized a roundtable for Utz, Fairtrade and Rainforest Alliance to discuss ways to scale up coordination, leading to a joint statement (ISEAL 2011). These organizations agreed not to criticize each other publicly anymore. In addition, they signed up for a pilot project involving shared training of auditors and a commitment to further investigate how to reduce the unhelpful consequences of implementation overlap at production facilities in various product categories. Coordination also revolves around the language of standards, in particular with regard to the issue of "living wage". In terms of harmonization of the kind that could prevent overlapping monitoring and enforcement, the main barrier, respondents agree, has now become the difference in auditing systems, with Utz and RA relying on quite similar accredited third-party audit companies, while FLO is sticking to its own auditing organization FLO-Cert. ${ }^{3}$

However, as respondents also note, the peculiar organizational structure of ISEAL creates a dilemma with regard to coordination of both a network-design and a marketdesign type. As a membership organization, it cannot run too far ahead of its base. Since many PSO members consider it appropriate to defend their unique features in comparison with their competitors, ISEAL staff cannot develop coordination efforts that are too isomorphic. ${ }^{4}$ For similar reasons, it is out of the question to use approaches to harmonization that would lead to clear statements about which ISEAL member is "better" or "more fair" than the other. ISEAL staff needs to stay within the boundaries of establishing what is good practice (and ask its members to abide by this). As a respondent notes "ISEAL does not rule who among us is the best, it is there to emphasize that we [as its members] all have something to add through our different approaches.". 5

Ultimately, ISEAL aims to increase positive recognition among the audience that grants authority to PSOs. This may principally consist of final consumers (especially in case of PSOs with consumer labels), retail and brand firms, national and local governments (especially if they procure goods standardized by PSOs) and international organizations (which can either further PSOs' causes or not get in the way of their efforts). Finally, donor organizations are significant. The vast majority of full ISEAL members currently depends on financing from governmental and intergovernmental development donors. ISEAL itself also receives substantial funding from such sources. Indirectly, among other things, these donors promote impact evaluation, so PSOs must have something to show for their efforts at the farm, plant and factory levels in terms of sustainability. In terms of PSO competition, donors also require continued commitment and progress towards reducing the harmful consequences of standard proliferation. ${ }^{6}$

\footnotetext{
2 Interviews with PSO representatives, June 2011; June 2012.

3 Interviews with PSO representatives, June 2012; June 2013.

4 Interviews with PSO representative, June 2011; brand representative, November 2011.

5 Interview PSO representative, June 2011.

${ }^{6}$ Interviews with evaluation consultant, June 2012; donor representative, June 2013.
} 


\section{Brand firms, standard professionals, baseline standards and scaling up}

Baseline standards are new standards describing appropriate sustainability practices in production. What makes them a market-design mode of meta-governance efforts rather than merely PSOs, which are a first-order form of sustainability governance, is that they are established to influence existing relevant private standards and as such affect transnational private sustainability governance at large. Baseline standards describe the minimums that could be considered credible as they approach social and environmental standard setting for PSOs in a particular issue area and/or industry. They therefore on the one hand attempt to put a normative floor under voluntary retail and brand firm efforts towards sustainable agriculture. On the other hand, they offer an easier stepping stone to improve sustainability for farmers supplying to retailers and brands, compared to supplying under PSOs' stringent requirements. Baseline standards can thus prevent a race to the bottom in standards from going too low, while increasing the scope of sustainability standard compliance in an industry. As such it is also a form of meta-governance suited for actors concerned about widening the scope of governance, and hoping to facilitate wider uptake of private standards. Meanwhile, PSOs and their most enthusiastic CSO and business supporters might be concerned that firms adopt baseline standards as a stand-alone solution to sustainable production, reducing demand for existing PSOs that have more stringent standards.

Over the past 5 years, more firms owning food brands-including Unilever, Kraft, Sara Lee and Mars-have set targets for further scaling up of the number of products they offer that have been sourced as compliant with existing sustainability standards. Largely, this move is attributed to concerns about the future of their markets. As one brand representative notes:

This is an issue of supply chain security. We do not have to emphasize the moral aspect of it; it is about doing good business. Where will all our coffee and cocoa be when we need to sell it to expanding markets in Asia and Latin America? ${ }^{7}$

Brand firms are concerned that in the future, demand for food will not match supply because of a lack of arable land-sourcing grounds. Up to now, the land use of many suppliers to global brands has not always been in line with prevailing scientific recommendations for sustained agriculture. Moreover, climate change at the local level, which affects soil, water supply and more, may endanger the quality of land for agricultural purposes. In addition, farmers in Latin America, Asia and Africa may decide to use their land for other purposes than production for branded buyers. Sustainability standards are a solution to unsustainable agricultural practice, and a way to secure supplier-buyer relationships. This is because certification to a standard also has business advantages for suppliers:

For us, sustainability standards are also of use because they increase quality and yield of the product. The farmer is then also happy; he produces more and receives a higher price for it. ${ }^{8}$

Scaling up of sustainability standards by global food brands requires existing PSOs to efficiently move larger bulks of farmers and their lands through standardization and certification procedures so that they can source to these brands. This requires scaling up of agricultural extension services, easier access to preharvest financing for farmers in

\footnotetext{
7 Interview with brand association representative, November 2011.

${ }^{8}$ Interview with brand representative, November 2011.
} 
developing countries, and more. But PSO competition is also a concern for brands. Multiple monitoring and enforcement by PSOs is inefficient and disturbs farm practices. Second, most PSOs demand that farmers contribute financially to the certification process, so multiple monitoring means multiple payments by farmers, and reduced farmer enthusiasm for certification by PSOs. ${ }^{9}$

As a result, global food brands push two agendas in terms of meta-governance that both serve the purpose of securing supply chains. First, brands seek the development of baseline standards. Such standards will make it possible for farmers to become certified more easily, at lower cost, according to standards that may substantially claim to do away with the most serious sustainability issues, while generating economic benefits for farmers. Such baseline standards could then potentially function as stepping stones for farms to subsequently graduate to more demanding certifications by Utz, RA or Fairtrade. ${ }^{10}$ Second, brands want PSOs to coordinate through roundtables, and to find effective solutions to overlapping implementation quickly (to be discussed in next section).

In their quest for baseline standards, brands are aided by technical standards professionals. A veritable industry has emerged of professionals developing, monitoring and consulting on standards for technical and quality conformance assessment. These professionals are increasingly used for governance of production and services. The main international institution for developing and maintaining such standards is ISO. Over the past two decades, sustainability standards have remained outside of the sphere of influence of ISO and technical standards professionals. Sustainability standards emerged as a result of civil society and industry activity. Professional auditors were the only party occupying both standard worlds. Recently, however, ISO has also ventured into corporate responsibility issues by developing a social responsibility standard, SR 26000. This move is interpreted as part of an ambition for developing this niche for business standard setting further, so that standards professionals can engage further in standard setting, certification, accreditation and advisory services. ${ }^{11}$ Accordingly, baseline standard meta-governance now occurs in coffee and cocoa, discussed in two separate subsections below.

\section{Coffee: roasters and baselines}

In 2003, the German developmental agency GTZ (Gesellschaft für Technische Zusammenfassung, now GIZ) began a multi-stakeholder dialogue programme, to which it invited large coffee roasters, a host of CSOs and representatives of coffee growers from around the world. The aim was to discuss the establishment of a common baseline code of conduct that could function as a first step for the mainstream coffee industry towards a more sustainable supply chain. The Common Code for the Coffee Community (4C) emerged out of this programme.

Ever since its inception, there has been discussion about 4C's function. Is it a programme that sets a baseline for the coffee industry, aids all existing PSOs and functions as a stepping stone towards sustainability certification by Utz, Fairtrade and/or RA? Or, is it a competitor to PSOs? Is it a first-order type of governance, or a second-order type of metagovernance? Could brands use $4 \mathrm{C}$ as a lenient alternative to existing and substantially more demanding PSOs $?^{12}$ These concerns remain today, as brands are presenting their numerical

\footnotetext{
9 Presentation by Lucas Simons, Dutch Sustainable Trade Initiative (IDH), November 2011.

${ }^{10}$ Interview note.

11 Interviews with ISEAL representative, June 2013; brand representative, June 2013.

12 Interviews with PSO representatives April 2011; 4C Representative, May 2011.
} 
targets for scaling up sustainability standards in their supply chains, and are including coffee verified by $4 \mathrm{C}$ as evidence of working towards that target. ${ }^{13}$ For instance, notably Tchibo and Nestlé have made progress by verifying large amounts of coffee according to the 4C standard. By 2009, over 500,000 tons were 4C-certified by these two brands (Kolk 2011). In comparison, for that year total worldwide Utz- and FLO-certified volumes were 306,000 and 165,000 tons, respectively.

$4 \mathrm{C}$ does not opt for a model that would lead to certification of the facilities in which it has implemented its code. Code compliance is checked through "verification", not certification. Nor does $4 \mathrm{C}$ opt for a product label that would communicate to a consumer audience that coffee had been grown and traded sustainably. $4 \mathrm{C}$ is to remain a business-tobusiness approach between growers and industrial buyers, and $4 \mathrm{C}$ verification is a sign of compliance with a baseline.

$4 \mathrm{C}$, however, further fuelled concerns about it being a stand-alone standard (or a firstorder type of governance) for scaling up sustainability, rather than a meta-governor, when it became a member of ISEAL as a PSO. ${ }^{14}$ This placed $4 \mathrm{C}$ on one level and in the same camp as PSOs. But through pilot projects with RA and Utz, and the involvement of coffeecertifying PSOs on its advisory board, 4C has emphasized the stepping stone character of its endeavour. ${ }^{15}$

By granting membership, ISEAL has been accommodating towards $4 \mathrm{C}$. At the time that 4C was established, ISEAL did not yet have an established organization. 4C was developed through a multi-stakeholder decision-making process that was inclusive in terms of types of interests represented and the geographic scope of partners at the table. It was therefore difficult for other PSOs to argue with the procedural legitimacy of the 4C effort, no matter their concern with the possibly competitive implications of 4C's emergence. ISEAL has not produced any policy statements that promote or discourage the use of baselining as a tool for meta-governance as a result of the emergence of $4 \mathrm{C}$.

On the basis of the discussion of events in coffee thus far, we might be tempted to consider the relationship between ISEAL and 4C not so much as rivalrous and politically contentious, but as complementary (although the relationship between 4C, and ISEAL members RA and FLO might be more complicated to define). And as such we may think of baseline standards and ISEAL's approach as mutually reinforcing (Zeitlin 2011), or each occupying their own niche (Abbott et al. 2013). However, as discussed below, ISEAL's position towards a new effort at baselining meta-governance for cocoa has been quite different. It shows an evolution in political positioning, revealing a tension between ISEAL and its members on the one hand, and emergent baseline standards on the other.

\section{Cocoa: technical standard professionals and baselines}

In 2011, the Danish Standards Foundation (DS) issued a tender for a European-level process for standardization of traceable and sustainable cocoa. This meant that the European Committee for Standardization (CEN) would start up a consultation process, researching the desirability and feasibility of such standards, and asking the opinion of its national standardization agency members (such as DS) and their stakeholders. CEN is the European counterpart to ISO, and as such is formally a nongovernmental organization; it

\footnotetext{
13 Interview with PSO representative, June 2013.

14 Interview with brand representative, October 2011.

15 Interview with 4C representative, May 2011; PSO representative, March 2011.
} 
is, however, the only organization mandated by the EU to develop private standards within its legal space (CEN 2012).

Confusingly, DS claims that there is "not yet a European or international standard for sustainable cocoa". In its tender, it does recognize the existence of PSOs such as Utz and Fairtrade that focus on sustainable cocoa, but it claims that a European standard "would complement these private [...] schemes by presenting a broad and public consensus on the specific criteria most relevant to all stakeholders... and unify requirements for the cocoa supply chain". (DS 2011) DS motivates the tender with reference to cocoa stakeholders that have communicated to DS that they are confused by standard fragmentation.

For this research, no interviewees were willing to verify on record that they were among the stakeholders offering input to DS, but all respondents consulted assumed that such input was given by chocolate brands. ${ }^{16}$

PSOs, in fear of yet another baseline standard, which, like 4C, could evolve into a semicompeting PSO, took action. On behalf of them, ISEAL publicly lobbied against the proposal, and issued a statement summing up the main perceived disadvantages of the CEN process: the creation of a standard that is less stringent than existing sustainability standards; the confinement of standardization to Europe, where cocoa is a globally produced and sold good; the development of a noninclusive standardization process; increased consumer confusion; and the diversion of attention and important resources of key stakeholders from the process of advancing sustainability in the industry. ISEAL therefore called upon industry and civil society to oppose the process (ISEAL 2012).

However, CEN approved DS's proposal and began the standardization process in 2012, claiming that a sufficient number of its member national standard agencies saw merit in the effort. Defeated in preventing the CEN process, ISEAL and its member PSOs such as Utz and RA joined in the consultation process on standardization-together with most major chocolate brands, some farmers, and a set of CSOs - as designated cocoa stakeholders and experts. Given the status of CEN as EU standardizer and its perceived legitimacy among government policymakers and industry players, these groups want to be included in formulation of the new baseline standard. ${ }^{17}$ According to the agreement among CEN and ISO, the final baseline standards, to be published at the end of 2015, will also be recognized as a new ISO standard. The standards will include criteria on sustainable production, traceability of products and appropriate conformity assessment (Steijn 2013). ${ }^{18}$

ISEAL's attempt to derail and stop meta-governance proliferation on behalf of its members has therefore failed. Currently, ISEAL is one of the parties giving input in a multi-stakeholder and multi-expert development process that will lead to meta-standards that functionally duplicate- but most likely slightly deviate from-its own effort to metagovern appropriate standard setting. And a concern for the future for ISEAL may be that whether other meta-governance attempts will emerge from the technical standards realm that may lead to duplicate meta-governance for other commodities. As such, the discussion of meta-governance in cocoa reveals that ISEAL does not welcome all new meta-

\footnotetext{
${ }^{16}$ Cf. interviews with CSO representative, March 2012; PSO representative, June 2012.

17 Interview with PSO representative, May 2012.

18 Bitzer et al. (2012) claim that for the cocoa industry, the World Cocoa Foundation also functions as a meta-governor due to its ability to link different stakeholders and partnership efforts and its ability to disseminate information. They, however, emphasize that WCF should be seen as a facilitator, not as a coordinator, rule-setter or a meta-standardizer for the sector.
} 
governance initiatives with open arms. Contrary to expectations in literature that would interpret meta-governance as complementary (Abbot et al. 2013; Zeitlin 2011), ISEAL may position itself strategically towards meta-governors with baselining ambitions, defending its own turf and the interests of its PSO members.

\section{Brands and multiplicitous roundtabling}

ISEAL includes the option of "roundtabling" as a network-design mode of meta-governance. In roundtable settings, representatives of PSOs debate what they can do to tackle problems of contradictory and overlapping implementation and duplicate costs for businesses being monitored and/or certified. The aim is to reduce overlapping PSO efforts, for instance, through joint training programmes of auditors, joint capacity-building programmes for producers seeking to get certified, mutual acceptance of audits and sharing of information of audit results. But ISEAL is not the only organization planning roundtables for PSOs. The emergence of a second roundtable effort can be explained by divergent interests of actors in scaling up sustainability of coffee. And the persistence with which actors promote their own version of roundtabling appears at odds with a rational problemsolving approach that would predict actors looking for efficiency and effectiveness in meta-governance.

The Dutch Sustainable Trade Initiative (Initiatief Duurzame Handel, IDH) is a product of an agreement signed by the Dutch government, civil society organizations and industry representatives in 2008. The aim is to scale up sustainability standard setting for international production. IDH is a discussion and experimentation forum addressing barriers to the scaling up of standards, including capacity building and the reduction in competition among PSOs. Different chapters of IDH focus on different sectors and their sustainability challenges. The participants within IDH chapters are predominantly brands, retailers and business interest groups, in collaboration with CSOs. IDH does not count PSOs among its participants, but is multi-stakeholder governed.

IDH was awarded a sizable sum of money (105 million euros) by the Dutch government, which it uses to match the additional equivalent investment of business players in scaling-up programmes (IDH 2012a). Because of this, IDH has suddenly become a sizable player in the European development aid funding market.

The discussion of a coffee programme within IDH began in 2009, and Dutch industry members adopted a global approach also involving Nestlé and Kraft, together with developmental CSOs. ${ }^{19}$ The IDH coffee programme is focused on harmonization of PSOs, as well as investment in capacity building in various coffee-growing regions, addressing climate change, and improving access to finance for growers (IDH 2012b). PSO competition is addressed through a planned roundtable forum for PSOs. A key pressure mechanism here is the involvement of significant industry players; IDH should, according to one of its representatives, "put these [standard] organizations in a room, lock the door, and not let them out until they agree." 20

Brand representatives promoting IDH consider ISEAL's approach to roundtabling to be slow and hesitant, in light of ISEAL's dependence on its members, and PSOs' emphasis on their autonomy and unique features. ${ }^{21}$ Business respondents explain that, much like baseline standards, effective roundtabling suits their agenda of securing supply:

\footnotetext{
19 Interviews with CSO representative, October, 2011; brand association representative, October 2011.

20 Interview with IDH representative, October 2011.

21 Interview with brand representative, October 2011.
} 
If we want to increase the speed of certification of supply base, we find private standard organizations here to be the problem rather than the solution, because they each stick to their own programs and approaches. So they need to come to agreements that do away with inefficiencies and counter-incentives. ${ }^{22}$

And a different respondent notes:

I can understand why ISEAL would be moving slowly in terms of having standard setters adjust to each other. They are a standard setters' interest group after all, they need to protect their base. But we would like for things to move faster. ${ }^{23}$

The IDH programme began to roll out over the course of 2013. In addition to hosting the coffee programme, IDH also functions as a funder for some programmes of $4 \mathrm{C}$ initiator GTZ in scaling up of sustainability efforts. IDH also financially supports one of the competing PSOs focused on coffee, Utz. As a donor of PSOs, a partner for development agencies, and a contractor for consultants, IDH wields significant influence.

Industry players now have both $4 \mathrm{C}$ and IDH as meta-governance routes towards scaling up sustainability in their coffee supply chains. For PSOs, two roundtables have been planned: one in which their interest group is in the lead (ISEAL) and one in which industry players (and to a lesser extent CSOs) take charge of the PSO competition agenda.

Representatives of Fairtrade, Utz, RA and ISEAL respond to this by referring to ISEAL as the appropriate forum for organizing harmonization. ISEAL and Utz representatives, however, also refer to IDH — with regard to its capacity building and funding ability —as a helpful partner in moving sustainability in production chains forward. ${ }^{24}$ Events surrounding IDH's coffee programme thus show that IDH on the one hand has complementary functions in meta-governance. But, next to this, IDH explicitly challenges ISEAL's metagovernance by offering a similar meta-governance instrument, for which its proponents claim it will do a better job than ISEAL. From a problem-solving perspective, this may be explained as a rational decision: actors prefer meta-governance initiatives that work best, and as a result this initiative then dominates over a less effective and efficient one. But, importantly, the claim to IDH's superiority in organizing roundtables is not technical nor economical. It has its roots in a political diagnosis of the strategic preference that ISEAL has for defending PSO's agendas, relative to the strategic position that multinational food brands have in speedy scaling of sustainability. For this reason being mindful of political contention in the interrelation between these two meta-governance efforts is arguably most appropriate in order to judge its further evolution.

\section{Global retail, benchmarking and multiplicitous comparison}

Major retailers have also adopted meta-governance strategies that pose a challenge to ISEAL's effort. Their approach to some extent duplicates some of ISEAL efforts, but operationalizes it in a manner leading to discomfort among some of ISEAL's members.

Rather than a direct concern for the sustainable future of the supply chain, most important drivers for engaging in meta-governance for retailers like Wal-Mart and Tesco are the expectations of the final consumer and the requirements of the law in consumer markets. If consumers or governments make particular demands about aspects of products,

\footnotetext{
22 Interview with brand representative, October 2011.

23 Interview brand representative, October 2011.

24 Interviews with PSO representatives April 2012; May 2012; May 2012.
} 
retailers need to respond to them. They will seek to prevent reputation damage or litigation. Using PSOs' labels and certificates in their stores is a way to manage expectations. Proliferation of and competition between PSOs is a nuisance because this makes such expectation management difficult. ${ }^{25}$

The Global Social Compliance Programme (GSCP), the most important retail metagovernance vehicle for sustainability standards in food products, was developed within the CIES (Comité International d'Entreprises à Succursales), nowadays the Global Consumer Goods Forum, the global association of multi-product retailers. A few years prior to that, CIES members had set up an equivalence process exclusively for food safety standards, the Global Food Safety Initiative (GFSI). Firm representatives then proposed that CIES would pioneer the development of a similar model for sustainability issues in production. ${ }^{26}$

GSCP offers an equivalence process, a market-design approach for which PSOs are invited to go through an analysis of how their model compares to reference standards. This benchmarking exercise results in scores, making PSOs substantially comparable for outside audiences, which may decide how preferable a PSO is based on its conformity to or deviation from a reference standard. This means that businesses, CSOs, governments and other parties can decide to adopt or promote a PSO based on its score in the equivalence process. Second, by showing what PSOs have in common, parties that are dealing with the dilemma of standard multiplicity, such as buying firms, can more easily manage a diversity of sustainability requirements.

In the short term, benchmarking can thus reduce confusion. In the long run, benchmarking can also lead to a race to the top, enthusiasts claim. This is the case if PSOs seek to score better than their competitors in comparison with the reference standards. Important in the establishment of an equivalence process is the question of the substance of the different reference standards. The common assumption is that these have a baseline quality, but one may debate how high this bar is set. GSCP's programme starts with a selfassessment by PSOs, and continues with a review of the self-assessment by an external expert. GSCP is now governed by among others Migros, Carrefour and Wal-Mart (GSCP 2009).

The publication of the first reference document, containing a code for labour practice, led to criticism of activist groups, pointing at inconsistencies in the provisions on freedom of association, wages and working hours (CCC 2007). The assurance aspect of the reference tools is also less specific than the ISEAL standard of good practice.

The GSCP has been underway since 2006, a point in time when ISEAL was still developing its meta-standards for good practice. GSCP is a project of large retailers, who are key business partners of ISEAL's members. Very few brands or PSOs can do without the cooperation of these retailers, which cater to a sizable part of the end consumer market. ${ }^{27}$ Because of this, ISEAL has not been belligerent towards GSCP.

For the first 3 years, it was not evident how GSCP would intervene in sustainability standard setting. What was evident was that global, powerful retailers were involved, in a development process largely excluding CSOs and that Wal-Mart, not known for its impressive sustainability track record, was among the initiators. This raised suspicion of a hijacking of standards by powerful business giants. ${ }^{28}$ "They are afraid of us", a

\footnotetext{
25 Interview with retail representative, June 2012.

26 Interview with retail representative, July 2012.

27 Interview PSO representative, June 2013; Interview GSCP representative, July 2012.

28 Interview with CSO representative, October, 2011; PSO representative, May 2011.
} 
global retail firm representative involved in GSCP quips, referring to ISEAL and its members. "They dread transparency, and the demands for it made by such crucial players like us". ${ }^{29}$

ISEAL and its members have reservations about other organizations ranking or scoring their efforts at governance relative to each other. For this reason, ISEAL members have for instance issued a press statement denouncing a comparative analysis by a German magazine which concluded that Fairtrade was more "fair" than competing standard organizations because of the price premium policy for farmers (Joint Response 2012). As representative of all its members, it is ISEAL's task to state that this position is too simplistic.

In the recent past, initiators of GSCP have reached out to ISEAL to discuss possible cooperation. Institutional linkage between both organizations would ensure that all ISEAL members would go through the equivalence process, while ISEAL would then be able to influence the set-up of GSCP. As such, ISEAL and GSCP could then become complementary and mutually reinforcing. But significantly, in light of the doubts of ISEAL's members described above, ISEAL has declined this offer. ${ }^{30}$ More recently, ISEAL and GSCP agreed to a more modest partnership. Their initial measurement and classification of standards of PSOs would come from a shared source, the International Trade Centre. ${ }^{31}$ After that, the GSCP meta-standards would guarantee retail recognition of the PSO. ISEAL is meanwhile developing its own standard comparison tool that shows how PSOs score according to different indicators of PSO credibility, without leading to generic end rankings (ISEAL 2013b). Note how retail recognition and PSO credibility are apparently judged by different meta-standards. The result is multiplicity in measurements and benchmarks, as one PSO respondent notes:

I get asked so often to inform a third party of how [my PSO] compares to competitors. This is really a lot of work, it drains resources. I also have to trust that this third party will use the info to create a fair and balanced comparison.[...] But what happens if a different standard setter gives false information to this third party, and comes out as more fair or strict or more compliant in the measures than [my PSO]? With ISEAL's work I know this won't happen, but with others I'm not sure. ${ }^{32}$

In sum, if problem-solving considerations had predominantly driven actor behaviour, or if convergent social-ideational dynamics had structured interaction among meta-governance policy makers, coordination among GSCP and ISEAL could have resulted. Instead, GSCP and ISEAL exist side by side, making similar demands on PSOs and their business participants at the same time, using similar modes of meta-governance, albeit using different meta-standards and instruments. Differences among (and lack of appetite for coordination between) meta-governors are motivated by a different diagnosis of the problem. This diagnosis has its roots in diverging political agendas: protecting individual PSO interests versus serving retailer compliance strategies.

\footnotetext{
29 Interview, June 2012.

30 Interview with GSCP representative, July 2012.

31 ISEAL and GSCP joint presentation, ISEAL Conference, London, June 2013.

32 Interview PSO representative; and with another PSO representative, June 2013.
} 


\section{Conclusion}

This paper has focused on meta-governance of coordination problems among competing PSOs that govern sustainable practices across borders. This meta-governance, as identified in the literature, is peculiar because it is predominantly performed by nongovernmental actors. But contrary to assumptions in existing studies, it is not determined by a single nongovernmental meta-governor (ISEAL). Rather, meta-governance is performed by a multitude of overlapping and sometimes inconsistent meta-governance initiatives, which mostly focus on quite similar modes of meta-governance, combining network-design with market-design instruments.

This paper has sought to explain this phenomenon of nongovernmental meta-governance multiplicity and duplicity. Prevailing theories of PSO interactions have difficulty accounting for this phenomenon. This is because meta-governance initiatives often discard the option of convergence, coordination or efforts at creating complementarity among themselves, which would be what problem-solving-focused and sociological-ideationally focused studies would predict.

Meta-governance initiatives are developed by actors with different positions in production chains and different priorities in PSO coordination, and therefore also different approaches within modes of meta-governance, which they seek to govern among a coalition of likeminded actors. Retailers therefore create their benchmark programmes in consideration of final markets, while brands pursue scaling up strategies with an eye on supply chain security, and PSOs pursue standards for appropriate standard setting to boost their credibility and external support. The result for PSOs is overlapping meta-governance through dissimilar meta-standards (such as GSCP and ISEAL), complex positioning towards varying baseline standards (such as CEN and 4C), and a struggle over whether brands or PSOs get to organize roundtable coordination.

This study therefore implies that for accurate depiction of meta-governance in transnational private sustainability governance specifically, it is important to take into account the interactive and dynamic effects of multiple and overlapping meta-governance efforts. Second, if scholars are interested in examining the political dimensions of metagovernance in this issue field, they should extend their attention to a variety of metagovernance efforts in order to uncover varying interests, coalitions, struggles and trade-offs in the design and re-design of meta-governance efforts.

The paper therefore speaks to the broader public policy literature on meta-governance by confirming that nongovernmental meta-governance exists, but that it quickly proliferates, and therefore could possibly lay the seeds of its failure. Self-governed meta-governance of self-governance possibly may reproduce rather than address coordination problems among governance arrangements. This may be the case even if most actors agree on the appropriate modes for meta-governing these coordination problems. This implies that there remain significant variations within these modes of meta-governance to which actors may respond more or less favourably. The paper therefore also makes a case for a more political view of meta-governance evolution within and across various modes of meta-governance.

In focusing on five initiatives interacting in agricultural chains, and zooming in on the significance of these interactions for two commodities, this paper merely describes and explains the tip of the iceberg in terms of existing meta-governance and interactions. The descriptive findings on meta-governance multiplicity are relevant for all commodity groups in sustainable agriculture, and may also extend beyond this sector, particularly since 
ISEAL, IDH and GSCP have a multi-industry focus. As the causal ambition has been to generate theory, the explanatory findings of the study of dynamics in cocoa and coffee serve as findings for these commodities, and as propositions for future research, focusing on meta-governance of private sustainability standards in other sectors. And beyond the field of sustainability issues, the paper offers inspiration for propositions on meta-governance of economic practices crossing jurisdictional borders, which may have nongovernmental meta-governance multiplying, and a varied set of actors and interests engaging in governance. This may include food safety governance, with the complex dynamic between GFSI and GlobalGAP.

Another issue for further study might be how the interactions among meta-governors in transnational private sustainability governance will evolve in the near future. Will ISEAL become further de-centered as a meta-governor or will it gain a more prominent position relative to other meta-governors? Will multiplicitous meta-governance succeed in increasing coordination among players? The approach and findings of this paper can inform further study on this subject.

Acknowledgments A previous draft of this paper was presented at the International Studies Association Annual Meeting in San Francisco, CA, April 42013 and at the University of Amsterdam PETGOV seminar, September 2013. I thank particularly Tim Bartley, Jessica Green, Alex Voicu and Jonathan Zeitlin for comments. This paper has also greatly benefited from comments by the editors of and blind peer reviewers for Policy Sciences. Part of the data gathering of this research was financed through a Jean Monnet Fellowship at the Robert Schuman Centre for Advanced Studies of the European University Institute.

Open Access This article is distributed under the terms of the Creative Commons Attribution 4.0 International License (http://creativecommons.org/licenses/by/4.0/), which permits unrestricted use, distribution, and reproduction in any medium, provided you give appropriate credit to the original author(s) and the source, provide a link to the Creative Commons license, and indicate if changes were made.

\section{References}

Abbott K. W., Green, J. F., \& Keohane, R. O. (2013). Organizational ecology in world politics: Conference paper, international studies association, San Francisco, April 2013.

Alter, K. J., \& Meunier, S. (2009). The politics of international regime complexity. Perspectives on politics, $7(1), 13-24$.

Auld, G. (2010). Assessing certification as governance: Effects and broader consequences for coffee. The Journal of Environment and Development, 19(2), 215-241.

Auld, G. (2014). Confronting trade-offs and interactive effects in the choice of policy focus: Specialized versus comprehensive private governance. Regulation and Governance, 8(1), 126-148.

Bartley, T. (2003). Certifying forests and factories: States, social movements, and the rise of private regulation in the apparel and forest products fields. Politics and Society, 31(3), 433-464.

Bartley, T. (2007). Institutional emergence in an era of globalization: The rise of transnational private regulation of labor and environmental conditions. American Journal of Sociology, 113(2), 297-351.

Bernstein, S. (2011). Legitimacy in intergovernmental and non-state global governance. Review of International Political Economy, 18(1), 17-51.

Biermann, F., Pattberg, P., van Asselt, H., \& Zelli, F. (2009). The fragmentation of global governance architectures: A framework for analysis. Global Environmental Politics, 9, 14-40.

Bitzer, V., Glasbergen, P., \& Leroy, P. (2012). Partnerships of a feather flock together? An analysis of the emergence of networks of partnerships in the global cocoa sector. Global Networks, 12(3), 355-374.

CCC. (2007). Letter to CIES and GSCP. Clean clothes campaign, Amsterdam. Accessed on file November 24, 2007.

CEN. (2012). About us. European committee for standardization, Brussels. https://www.cen.eu/cen/ AboutUs/Pages/default.aspx. Accessed April 5, 2012.

Derkx, B., \& Glasbergen, P. (2014). Elaborating global private meta-governance: An inventory in the realm of voluntary sustainability standards. Global Environmental Change, 27, 41-50. 
Dingwerth, K. (2008). Private transnational governance and the developing world: A comparative perspective. International Studies Quarterly, 52(3), 607-634.

Dingwerth, K., \& Pattberg, P. (2009). World politics and organizational fields: The case of transnational sustainability governance. European Journal of International Relations, 15(4), 707-743.

DS. (2011). Traceable and sustainable cocoa. Danish Standards Foundation, Copenhagen. www. standardsproposals.bsigroup.com/Home/1072. Accessed April 11, 2012.

Fransen, L. (2011). Why do private governance organizations not converge? Governance, 24(2), 359-387.

George, A. L., \& Bennett, A. (2005). Case studies and theory development in the social sciences. Cambridge, MA: MIT Press.

Gereffi, G., Humphrey, J., \& Sturgeon, T. (2005). The governance of global value chains. Review of International Political Economy, 12(1), 78-104.

Gerring, J. (2007). Case study research: Principles and practices. Cambride, MA: Cambridge University Press.

Glasbergen, P. (2011). Mechanisms of private meta-governance: An analysis of global private governance for sustainable development. International Journal of Strategic Business Alliances, 2(3), 189-206.

GSCP. (2009). GSCP boards. Global Social Compliance Programme, Issy-les-Moulineaux. http://www. ciesnet.com/1-wweare/1.4-committees/gscpboards.asp. Accessed February 3, 2010.

Gulbrandsen, L. H. (2014). Dynamic governance interactions: Evolutionary effects of state responses to non-state certification programs. Regulation and Governance, 8(1), 74-92.

IDH. (2012a). What we do. Initiatief Duurzame Handel, Utrecht. http://www.idhsustainabletrade.com/whatwe-do. Accessed March 12, 2012.

IDH. (2012b). Coffee. Initiatief Duurzame Handel, Utrecht. http://www.idhsustainabletrade.com/coffee. Accessed July 16, 2012.

ISEAL. (2011). Joint agreement. International social and environmental accreditation and labelling Alliance. http://www.isealalliance.org/resources. Accessed April 3, 2011.

ISEAL. (2012). Proposal to elaborate a new CEN standard on cocoa. International social and environmental accreditation and labelling Alliance. http://www.isealalliance.org/resources/iseal-cocoa-cen-submisison. Accessed May 3, 2012.

ISEAL (2013a). Global agreement on how to identify credible ecolabels. International social and environmental accreditation and labelling Alliance. http://www.isealalliance.org/online-community/news/ global-agreement-on-how-to-identify-credible-ecolabels. Accessed June 15, 2013.

ISEAL. (2013b). Sustainability standards comparison tool. International social and environmental accreditation and labelling Alliance. http://www.isealalliance.org/sites/default/files/SSCT\%20Fact\%20Sheet $\%$ 20Revised\%2011.13.pdf. Accessed December 13, 2013.

Jenkins, R. (2002). The political economy of codes of conduct. In R. Jenkins, R. Pearson, \& G. Seyfang (Eds.), Corporate responsibility and labor rights: Codes of conduct in the global economy (pp. 13-30). London: Earthscan.

Jessop, B. (2003). Governance and meta-governance: On reflexivity, requisite variety and requisite irony. In H. P. Bang (Ed.), Governance as social and political communication (pp. 101-116). Manchester: Manchester University Press.

Jessop, B. (2011). Metagovernance. In M. Bevir (Ed.), Handbook of governance (pp. 106-123). London: Sage.

Joint Response to Okotest article. (2012). https://www.utzcertified.org/en/newsroom/utz-in-the-news/ 26582670-2012-08-07-15-30-40. Accessed March 3, 2013.

Keohane, R. O., \& Victor, D. G. (2011). The regime complex for climate change. Perspectives on Politics, $9(1), 7-23$.

Kolk, A. (2011). Mainstreaming sustainable coffee. Sustainable Development,. doi:10.1002/sd.507.

Kollman, K., \& Prakash, A. (2002). EMS-based environmental regimes as club goods: Examining variations in firm-level adoption of ISO 14001 and EMAS in UK US and Germany. Policy Sciences, 35(1), 43-67.

Loconto, A., \& Fouilleux, E. (2013). Politics of private regulation: ISEAL and the shaping of transnational sustainability governance. Regulation and Governance. doi:10.1111/rego.12028.

Marx, A., \& Wouters, J. (2014). Competition and cooperation in the market of voluntary sustainability standards. UNFSS Discussion papers. https://ghum.kuleuven.be/ggs/publications/working_papers/ new_series/wp131-140/wp135-marx-wouters.pdf. Accessed April 22, 2014.

Mutersbaugh, T. (2005). Fighting standards with standards: Harmonization, rents, and social accountability in certified agrofood networks. Environment and Planning A, 37(11), 2033-2051.

Overdevest, C. (2010). Comparing forest certification schemes: The case of ratcheting standards in the forest sector. Socio-Economic Review, 8, 47-76. 
Peña, A. M. (2014). Governing differentiation: On standardisation as political steering. European Journal of International Relations, . doi:10.1177/1354066114523657.

Peters, B. (2009). The two futures of governing: Decentering and recentering processes in governing. NISPAcee Journal of Public Administration and Policy, 2(1), 7-24.

Peters, B. G. (2010). Meta-governance and public management. In S. P. Osborne (Ed.), The new public governance: Emerging perspectives on the theory and practice of public governance (pp. 50-64). London: Routledge.

Porras-Gómez, A. M. (2014). Metagovernance and control of multi-level governance frameworks: The case of the EU structural funds financial execution. Regional and Federal Studies, 24(2), 173-188.

Porter, T., \& Ronit, K. (2006). Self-regulation as policy process: The multiple and criss-crossing stages of private rule-making. Policy Sciences, 39(1), 41-72.

Potts, J., Van Der Meer, J., \& Daitchman, J. (2010). The state of sustainability initiatives review 2010: Sustainability and transparency. Winnipeg: International Institute for Sustainable Development.

Raynolds, L., \& Long, M. (2007). Fair Alternative trade: Historical and empirical dimensions. In L. Raynolds, D. Murray, \& J. Wilkinson (Eds.), Fair trade: The challenges of transforming globalization (pp. 15-29). London: Routledge.

Reinecke, J., Manning, S., \& Von Hagen, O. (2012). The emergence of a standards market: Multiplicity of sustainability standards in the global coffee industry. Organization Studies, 33, 613-632.

Schleifer, P. (2013). Orchestrating sustainability: The case of European Union biofuel governance. Regulation and Governance, 7(4), 533-546. doi:10.1111/rego.12037.

Sørensen, E. (2006). Metagovernance the changing role of politicians in processes of democratic governance. The American review of public administration, 36(1), 98-114.

Steijn, J. (2013). The new ISO/CEN standard on sustainable and traceable cocoa. ICCO workshop on certification. Douala, June 25th, 2013. http://www.icco.org/about-us/international-cocoa-agreements/ cat_view/68-icco-workshops-and-seminars/69-certification-workshop-douala-cameroon-june-2013.html. Accessed January 23, 2014.

Steurer, R. (2013). Disentangling governance: A synoptic view of regulation by government, business and civil society. Policy Sciences, 46(4), 387-410.

Wouters, J., Marx, A., \& Hachez, N. (2012). Private standards, global governance and international trade: The case of global food safety governance. In A. Marx, M. Maertens, \& J. Wouters (Eds.), Private standards and global governance: Economic, legal and political perspectives (pp. 255-292). Cheltenham: Edward Elgar.

Zeitlin, J. (2011). SASE annual meeting 2010. Philadelphia. Pragmatic transnationalism: Governance across borders in the global economy. Socio-Economic Review, 9(1), 187-206. 